\title{
Makine çevirisi sonrası düzeltme işlemine (post-editing) yönelik kapsamlı bir inceleme
}

\section{Caner ÇETİNER ${ }^{1}$}

\begin{abstract}
APA: Çetiner, C. (2019). Makine çevirisi sonrası düzeltme işlemine (post-editing) yönelik kapsaml bir inceleme. RumeliDE Dil ve Edebiyat Araşturmaları Dergisi, (Ö6), 462-472. DOI: 10.2900o/rumelide.649333
\end{abstract}

\section{$\ddot{O} \mathbf{z}$}

Makine Çevirisine yönelik son yllarda artan bir talep görülmektedir. Diğer bir ifadeyle makine çevirisi sistemlerindeki güncel gelişmeler hem çeviri piyasasında hem de çeviriye ilişkin akademik çevrelerde ilgi uyandırmıştır. Böylece, bir zamanlar ALPAC raporuyla kesintiye uğrayan "Tam Otomatik Yüksek Kalitede Makine Çevirisine” yönelik umutlar tekrar canlanmıştır. Ancak farklı birçok deneysel çalışmada ortaya konduğu üzere makine çevirisi sistemleri henüz, herhangi bir düzeltme gerektirmeden kolayca yayımlanabilir çeviri ürünleri ortaya koyacak durumda değildir. Bu şartlar altında "Makine Çevirisi Sonrası Düzeltme İşlemi” (Post-Editing) isimli yeni bir araştırma alanı ortaya çıkmıştır. Literatürdeki en yaygın tanıma göre post-editing, makine çevirisi tarafından çevrilen bir metnin düzeltilmesi veya değiştirilmesi anlamına gelmektedir. Bu tanım normal bir çevirmen ile Makine Çevirisi Sonrası Düzeltme İşlemini (post-editing) gerçekleştiren çevirmen arasındaki ayrıma dikkat çekmektedir. Ayrıca, ilgili alanyazında belirtildiği üzere, nihai çeviri ürününün kalitesi büyük ölçüde makine çevirisinden çıkan ham çeviriye bağlıdır. Bu yüzden kontrollü dil kuralları veya ön-düzeltme adımları gibi parametreler makine çevirisinden çıan ham çevirinin yüksek kalitede olmasını sağlayan etkenler olarak ön plana çıkmıştır. Ayrıca, çevirmenin rolü ve dahil olduğu süreç dikkate alındığında Makine Çevirisi Sonrası Düzeltme İşlemi, Çeviribilimde yeni paradigma değişimlerinin yolunu açmıştır. Ancak, tüm bu hususlar ve kavramlar ilgili alanyazında birbirinden bağımsız olarak açıklanmaktadır. Bu yüzden bu çalışma betimleyici bir metotla bu kavramları kapsamlı olarak ele almayı, birbirleriyle ilişkilendirmeyi ve Makine Çevirisi Sonrası Düzeltme İşleminin yerini Çeviribilimdeki dönemler açısından incelemeyi amaçlamaktadır.

Anahtar kelimeler: Makine çevirisi, makine çevirisi sonrası düzeltme işlemi (post-editing), öndüzeltme işlemi, kontrollü dil kuralları.

\section{A comprehensive review of the machine translation post-editing}

\begin{abstract}
The recent years have witnessed the increasing popularity of Machine Translation systems. In other words, the latest developments seen in Machine Translation systems have aroused growing interest both in the translation industry and translation academia. Thus, the hope for Fully Automatic HighQuality Machine Translation System, which was lost with the infamous ALPAC report, has cherished again. However, as experimented with different studies, it was proven that Machine Translation systems do not yield the expected high-quality translation products that are easily publishable without any editing. As such, a new research area emerged to be called as "Machine Translation PostEditing”. According to its most common definition, Post-Editing refers to a process in which post-
\end{abstract}

$1 \quad$ Arş. Gör. Dr., Kırıkkale Üniversitesi, Fen Edebiyat Fakültesi, Batı Dilleri ve Edebiyatları Bölümü, İngilizce Mütercim Tercümanlık ABD (Kırıkkale, Türkiye), canercetiner88@gmail.com, ORCID ID: oooo-ooo3-0414-8451 [Makale kayıt tarihi: 06.10.2019-kabul tarihi: 20.11.2019; DOI: 10.29000/rumelide.649333] 
editor edits, corrects or modifies a text that is translated by Machine Translation System. This highlights a significant difference between the work of a post-editor and a translator. Furthermore, as stated in the relevant literature, the quality of the final translation product depends on the quality of "raw machine translation output" to a great extent. Thus, the parameters like controlled language rules or pre-editing steps become prominent to have a high-quality machine translation output. Moreover, Post-Editing has paved the way for new paradigms in Translation Studies considering the role of translator and the process involved. However, all of these considerations and concepts are given in the relevant literature not in an integrated way but separately. Thus, this study aims to shed light on these concepts with a comprehensive manner and investigate the place of Post-Editing within the Turns of Translation studies with a descriptive method.

Keywords: Machine translation, post-editing, pre-editing, controlled language rules.

\section{Giriş}

Çeviri, teknolojik gelişmelere daima açık ve tepki veren bir çalışma alanı olmuştur. Bu bağlamda incelendiğinde özellikle küreselleşmeyle doğan artan iş hacminin karşılanabilmesi için son otuz yılda teknoloji profesyonel çevirmenlerin çevirdikleri içeriği ve çeviri yapma biçimlerini kökten biçimde değişikliğe uğratarak yeni çevirmen modellerinin ortaya çıkmasını sağlamıştır (Folaron, 2010; Gambier, 20014). Bu yeni çevirmen modelinde çevirmenlerden farklı edinçlere sahip olmaları ve bunları birbirleriyle ilişkilendirerek kullanmaları beklenmektedir. Ayrıca çevirmenlerin daha önceleri bilinen kültür edinci, dil edinci gibi edinçlerin yanında teknoloji edinci, araştırma edinci ve proje yönetim bilgisi edinci gibi alt edinçlere sahip olmaları istenir hale gelmiştir (Balkul \& Toptan, 2019). Bunlarla birlikte çevirmenlerin çalıştıkları araçlar da değişikliğe uğrayarak profesyonel çeviri uğraşı bir tür "insan ve bilgisayar arasındaki etkileşim” olarak tanımlanır hale gelmiştir (O'Brien 2012). Ancak makine çevirisi gibi çevirinin karakterini baştan değiştiren gelişmelerin etkisi son yllarda elde ettiği sonuçlarla bu etkileşimi daha ileri bir boyuta taşımıştır. Bu anlamda makine çevirisinde görülen iyileştirmeler hem akademik çeviri eğitimi hem de profesyonel çeviri piyasası bağlamında dikkate değer birçok gelişmeye kapı aralamıştır.

Bu hususlar dikkate alındığında bir zamanlar yüksek kalite beklentileriyle büyük umutlar bağlanan ancak ALPAC raporuyla yatırımların kesildiği makine çevirisi konusu tekrar gündeme gelmiştir. Bunun üzerinde Google çeviri hizmeti gibi görünürlüğü yüksek makine çevirisi sistemlerindeki iyileştirmelerin etkisi büyüktür (Reichert, 2016). Ayrıca makine çevirisi sistemlerinin günden güne artan çeviri işlerini karşılayabilmede çeviri şirketlerinin kullandığı olmazsa olmaz bir araç haline gelmesinin de bunda payı büyüktür (Vashee, 2013). Dolayısıyla makine çevirisi artık uzak bir hayal değil bir ihtiyaç olarak görülmektedir. Ancak yapılan çalışmalarda makine çevirisinden çıkan ham çeviri metninin henüz kendi başına yeterli kalitede olmadığı görülmektedir (Fiederer \& O’Brien, 2009). Bu yönde Kovačević (2014) "eğer yayınlanacak derecede kaliteye ulaşılmak isteniyorsa mevcut tüm ticari ve işlevsel makine çevirisi sistemlerinin düzeltilmesi gereken çeviriler ürettiğine dair" Hutchins (2001) tarafından ortaya konan ifadenin hala geçerliliğini koruduğunu belirtmektedir. Bu yüzden profesyonel çeviri alanında makine çevirisi sistemlerinden çıkan çevirilerin düzeltilmesini kapsayan yeni bir iş dalı ortaya çıkmıştır. Bu iş dalı ilgili alan yazında "post-editing" olarak ifade edilmiştir (Allen, 2003). Ayrıca alan yazındaki tanımlara bakıldığında Makine Çevirisi Sonrası Düzeltme işlemini (post-editing) yapan çevirmenlerin sahip olması gereken beceriler ve bilgi birikimi diğer çevirmenlere göre farklılık gösterebilmektedir (Celia Rico \& Torrejón, 2012). Bunun yanında makine çevirisinden çıkan ham çevirinin kalitesinin, nihai çeviri kalitesi üzerinde büyük etkiye sahip olduğu farklı araştırmalarla kanıtlanmıştır. Bu sebeple ham 
çeviri metnini makine çevirisine uygun hale getirme amacıyla kontrollü dil kuralları ya da ön-düzeltme işlemi gibi farklı uygulamalardan yararlanılmaktadır (Doherty, 2012; C Rico \& Torrejon, 2004).

Ayrıca makine çevirisinde son yıllarda görülen bu gelişmeler Çeviribilim açısından değerlendirildiğinde çevirmenin rolü ve çevirinin yapılışı bakımından yeni bir dönemece girildiği, çeviriye dair tanımlamalara eklemeler yapılması gerektiği görülmektedir. Bunun yanında akademik çeviri eğitimi veren kurumların makine çevirisindeki gelişmeler karşısındaki tutumları, bu gelişmelerin içselleştirilmesi bağlamında büyük öneme sahiptir. Bu sebeple bu kurumların gelişmeler karşısındaki duruşlarının incelenmesi ileriye yönelik atılacak adımları belirleme açısından önemlidir. Tüm bu hususlar dikkate alındığında bu çalışmada ilk olarak 1960'lardan başlayarak makine çevirisinin geçirdiği evrim ve makine çevirisine bakış açısındaki değişim ele alınmaktadır. Daha sonra nihai çevirinin kalitesi bağlamında Makine Çevirisi Sonrası Düzeltme İşlemi (post-editing), ön-düzeltme (pre-editing) ve kontrollü dil kuralları (controlled language rules) gibi kavramlar arasındaki ilişkiye betimleyici bir metotla değinilmektedir. Çalışmanın ilerleyen kısımlarında ise akademik çeviri eğitimi veren kurumların mevcut durumlarına odaklanılmaktadır.

\title{
2. Geçmişten günümüze makine çevirisi
}

Makine çevirisi, Decartes'in 1629 yılında bir dilin kodlar aracılığıyla temsil edilebileceğini ve farklı dillerdeki aynı anlama gelen kelimelerin aynı kodları paylaşabileceğini söylemesi gibi üzerinden yaklaşık dört yüz yll geçen öncül söylemlere rağmen somut adımlar dikkate alındığında elli yıllık bir geçmişe sahiptir (Quah, 2006, s.58). Dolayısıyla çevirinin otomatikleştirilmesine ya da mekanik çeviriye yönelik öne sürülen fikirler daha öncelere dayansa da günümüzün mantığını yansıtan bir makine çevirisi sistemini yaratmaya yönelik ilk somut adım Soğuk Savaş döneminin başlarında (1940-1950 arasında) atılmıştır.

Dijital bilgisayarların kapasitelerinin anlaşılmasıyla birlikte Soğuk Savaş döneminde bu kapasitenin çeviri için kullanılabileceği fikri doğmuştur (Pugh, 1992). Bu dönemde makine çevirisi sistemlerini geliştirmenin arkasında sadece siyasi değil aynı zamanda bilimsel gerekçeler de yatmaktadır. Bu anlamda Gordin (2016) Soğuk Savaş döneminin ilk ylllarında çevirinin otomatikleştirilmesine yönelik dil ve bilim alanında bir dizi hikâye ve gerekçenin iç içe geçtiğini ve birbirini pekiştirdiğini şöyle belirtir:

\begin{abstract}
Bir tarafta Sovyetlerin 1949 yılındaki sürpriz nükleer denemesine kadar uzanan endişe hâkimdi. Soğuk Savaş adeta bilimsel bir yarış alanı halini alıyordu. 1950'lerde Sovyetler Dünyanın en büyük bilim alt yapısına sahip hale gelmişti ve bunu yayımlanan eserlerden takip etmek mümkündü. Fakat Amerikalılar açısından bakıldığında pratikte Rusça gibi büyük bir engel vardı. Bu yüzden 1945’te silahlar susar susmaz Amerikan bilim kurumları kendilerini bilimsel bir dil sıkıntısının ortasında buldular (s.209).
\end{abstract}

Amerika’nın nükleer alandaki üstünlüğünü sürdürebilmesi ve Sovyetlerin kendisine ne zaman yetişebileceğini tahmin etmesi Sovyetlerde yayınlanan bilimsel araştırma dergilerini taramasına bağlıydı. Dolayısıyla bu gibi gerekçelere bakıldığında, Bellos (2011) Avrupa'daki diğer dillerin gelişiminin aksine makine çevirisinin Soğuk Savaş’ın başlangıcında siyasi bir ihtiyaç olarak doğduğuna vurgu yapmaktadır.

Tarihçesi kısaca böyle ele alınan makine çevirisinin tanımına bakıldı̆̆ında ise Qun \& Xiaojun (2015) makine çevirisini, bir doğal dilden bir başka doğal dile metin veya konuşmayı çevirmede yazılım kullanımını araştıran Bilgisayarlı Dilbilim veya Doğal Dil İşleme alanının bir alt dalı olarak tanımlar. Ancak makine çevirisi, çoğu zaman Bilgisayar Destekli Çeviri (BDÇ) ya da Çeviri Belleği (ÇB) gibi 
çevirmenlerin işini kolaylaştıran diğer araçlarla karıştırılmaktadır (Forcado, 2010). Bu sebeple makine çevirisini diğer araçlardan ayırma noktasında Hutchins \& Somers (1992) tarafından oluşturulan ve Şahin (2013) tarafından Türkçeye aktarılan aşağıdaki diyagramdaki kavramları açıklamakta yarar vardır.

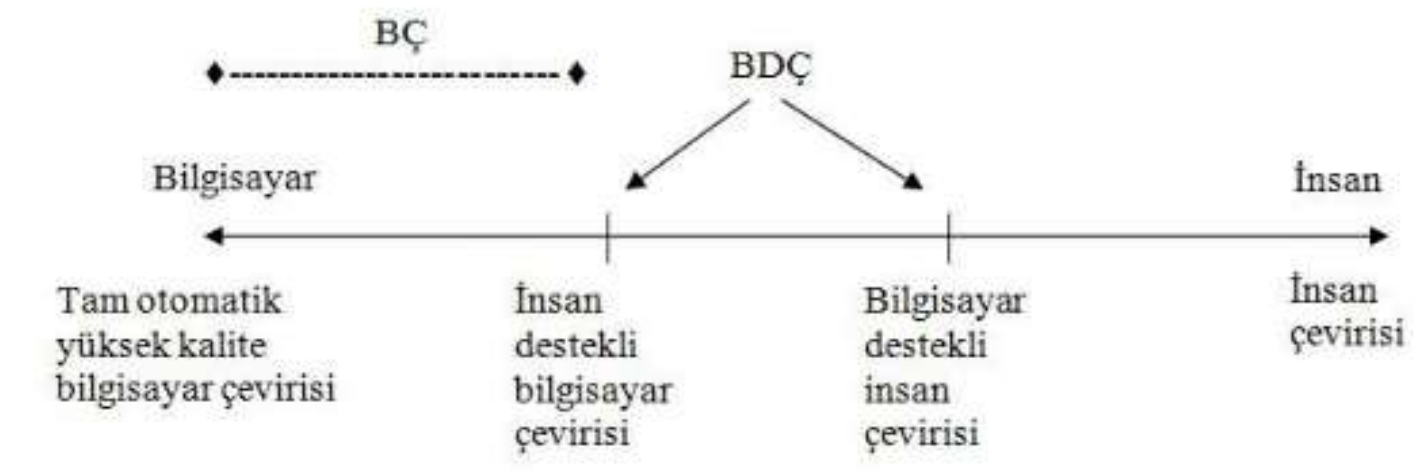

$\mathrm{BC}=$ = bilgisayar çevirisi: $\mathrm{BDC}$ : bil gisayar destekli çeviri

Şekil 1. Çevirinin yapana göre sınıflandırılması (Şahin, 2013,s.13)

Diyagram tarihsel süreç içerisinde ele alındığında makine çevirisi üzerine yapılan çalışmaların diyagramın bir ucunda yer alan Tam Otomatik Yüksek Kalite Makine Çevirisi hayaliyle başladığı görülmektedir. Bu anlamda Yehoshua Bar-Hillel ve Leon Dostert gibi doğrudan bu konuyu araştırmak için görevlendirilen araştırmacıların ortaya koyduğu makine çevirisi sisteminin 1954 yılında 49 cümleyi Rusçadan İngilizceye başarılı şekilde çevirdiği bildirilmiştir (Chan, 2015). Bu başarılı gösterimden sonra makine çevirisi ABD'de milyon dolarlık bir konu haline gelmiş ve on yll içerisinde Dünyanın farklı yerlerinde makine çevirisi araştırma grupları kurulmuştur. Bu araştırma gruplarının neredeyse hepsinin amacı Tam Otomatik Yüksek Kalitede Makine Çevirisine erişmekti. Ancak 1966 yılında Amerikan Ulusal Bilimler Akademisi tarafından kurulan ve Türkçesi Otomatik Dil İşleme Danışma Kurulu olan ALPAC (Automatic Language Processing Advisory Committe) yayınladığı meşhur raporla makine çevirisine dair yakın gelecekte beklenen kaliteye ulaşmanın imkânsız olduğunu ortaya koymuştur. Ayrıca bu kurul, yatırımların doğrudan makine çevirisi yerine temel dilbilimsel araştırmalara ve insan çevirisini geliştirecek metotlara yöneltilmesi gerektiğini vurgulamıştır. Çoğu araştırmacı tarafından dar kapsamlı ve taraflı olmasıyla eleştirilen rapor neyse ki başka ülkelerde makine çevirisi üzerine yapılan çalışmaları tamamen durduramamıştır. Ancak bu raporla birlikte makine çevirisi çalışmaları bir sonraki on yıl içerisinde sessizliğe bürünmüştür (Qun \& Xiaojun, 2015). Makine çevirisine dair büyük umutların boşa çıkmasını Hutchins (1995) uzun süreli temel düzeyde araştırma olmaksızın ve gerek metinleri hazırlamada gerekse ham çeviri metnini düzeltmede insan desteği olmadan Tam Otomatik Çevirinin mümkün olmayacağı şeklinde yorumlamıştır. Bu yorum ilerde post-editing (Makine Çevirisi Sonrası Düzeltme) olarak adlandırılacak bir çalışma dalının yolunu açmıştır.

\section{Makine çevirisi sonrası düzeltme (post-editing) işlemi}

Makine çevirisinin gerek büyük çapta çeviri hizmeti sunan şirketler gerekse bireysel kullanıcılar tarafından yoğun biçimde kullanılması Makine Çevirisi Sonrası Düzeltme İşlemini (post-editing) çeviri sürecinin vazgeçilmez bir aracı haline getirmektedir. Mellinger (2017) tarafından aktarıldığına göre 
2012 yllında dil hizmeti sağlayan şirketlerin yaklaşık yüzde 40’ı post-editing hizmeti satmıştır. Benzer şekilde makine çevirisine yönelik piyasa analizlerine bakıldığında makine çevirisinin 2022 yllında yaklaşık bir milyar dolarlık bir iş kolu haline geleceği tahmin edilmektedir (Munteanu, 2016). Tüm bu hususlar dikkate alınarak geçmişten günümüze "post-editing" tanımlarına bakılmasında ve çevirmenlerin sahip olması gereken becerilere tekrar odaklanılmasında yarar vardır.

Mossop (2014), post-editing işlemini insanın makine çevirisinden çıkan "ham çeviri metnini" düzeltmesi olarak tanımlar. Post-editing işlemini normal çeviriden ayıran nokta, post-editing işleminde önceden makine tarafından çevrilen bir metnin var olmasıdır. Dolayısıyla "ham çeviri metni" adında bir ara ürün vardır. Chan (2004) ise post-editing işlemini makine çevirisinden çıkan ham metnin kullanıma hazır hale getirilmesi olarak tanımlamıştır. Bu noktada kullanıma hazırlık kavramı, makine çevirisinin kullanım amacı bağlamında yorumlandığında J. Hutchins (2003) tarafından ortaya atılan "assimilation", "dissemination" ve "interchange" sınıflandırmasının günümüz çerçevesinde yeniden ele alınması gerekir. Şahin (2013) "assimilation" kavramına "benzeşim"; "dissemination" kavramına "dağıtım"; "interchange” kavramına ise "değiş tokuş" karşılığını vermiştir (s.78). Ancak burada "assimilation" kavramıyla makine çevirisi kullanılarak metnin özünün genel hatlarıyla anlaşılması ifade edilmektedir. Diğer bir ifadeyle "gisting" yani ana fikrin anlaşılması vurgulanmaktadır. Burada kullanıcı açısından bakıldığında metnin yayımlanması amacı yoktur. Metin sadece belirli bir kişi veya kişiler için çevrilmektedir. "Dissemination" kavramıyla ise makine çevirisi kullanılarak metnin yayımlanabilecek kaliteye getirilmesi amacı güdülmektedir. Yani bu kavram metnin daha geniş kitlelere ulaşmasını öngörmektedir. Üçüncü tür olan "interchange" kavramı ise telefon görüşmelerinde veya yazışmalarda katılımcılar arasındaki iletinin makine çevirisi tarafından çevrilmesine gönderme yapmaktadır. $\mathrm{Bu}$ kavramları yeniden Türkçeye çevirmek gerekirse "assimilation" kavramına "anlama"; dissemination" kavramına metnin ulaştığı kitle de dikkate alınarak "yayma"; interchange kavramına ise "aktarma" denebilir.

"Anlama" amacına göre makine çevirisinin kullanımı genellikle hızlıca yapılan büyük çapta düzeltilmemiş çeviriler ortaya koymaya yöneliktir. "Yayma" amacıyla kıyaslandığında "anlama" amacıyla kullanım daha az maliyetlidir ve daha hızlıdır. Burada çeviri maliyetlerinin düşük tutulması ana hedeftir. "Aktarma" amacının gerekçesi ise çevirmenlerin anında ortaya çlkan "gerçek zamanlı" çeviri ihtiyacını karşılamada çektikleri zorluklardır. Burada da çevirinin kalitesi ikinci planda tutulur (Quah, 2006).

Makine çevirisinin bu derece sık kullanılmaya başlamasıyla birlikte ortaya çıkan ham çeviri metnine ilişkin kalite olgusu farklı çalışmalarda araştırma konusu olmuştur (Fiederer \& O’Brien, 2009). Bu anlamda Kontrollü Dil Kuralları (Controlled Language Rules) ve Ön-düzeltme işlemi (Pre-editing) adında iki uygulama öne çıkmaktadır. Gerek insan çevirisinde gerekse makine çevirisinde kontrollü dil kullanımının, çevrilebilirlik ve okunabilirlik bağlamında makine çevirisinden çıkan metnin kalitesini iyileştirdiği gösterilmiştir (Nyberg, Mitamura, \& Olaf Huijsen, 2003). Ön-düzeltme işleminin kapsamına muğlak veya karmaşık cümle yapılarının sadeleştirilmesi girerken kontrollü dil kurallarının kapsamına ise muğlaklığa ve karmaşıklı̆̆a neden olmayacak yazım kurallarının geliştirilmesi girmektedir.

\section{1. "Post-editing” ile değişen çeviri süreci ve çevirmenden beklenen beceriler}

Makine Çevirisi Sonrası Düzeltme İşlemi (post-editing) bir önceki bölümde değinilen tanımlara göre çeviri süreci açısından ele alındığında daha önce bilinmeyen ham metin (raw output) kavramı ortaya 
çıkmıştır. Dolayısıyla çevirmenlerin önünde artık kaynak metin değil bir ara metin yani tamamlanmamış, yarım bir çeviri olmaktadır. Ancak burada "post-editing” işleminin çeviride düzeltme veya editörlük işi ve süreciyle karıştırılmaması gerekir. Zira bir editöre iş olarak çevirinin nihai hali verilirken makine çevirisinden çıkan metin nihai olarak değerlendirilmemektedir (Loffler-Laurian, 1996; O’Brien, 2006). Bu bağlamda aşağıdaki resimde post-editing süreci ile normal bir çeviri süreci kiyaslanmıştır.

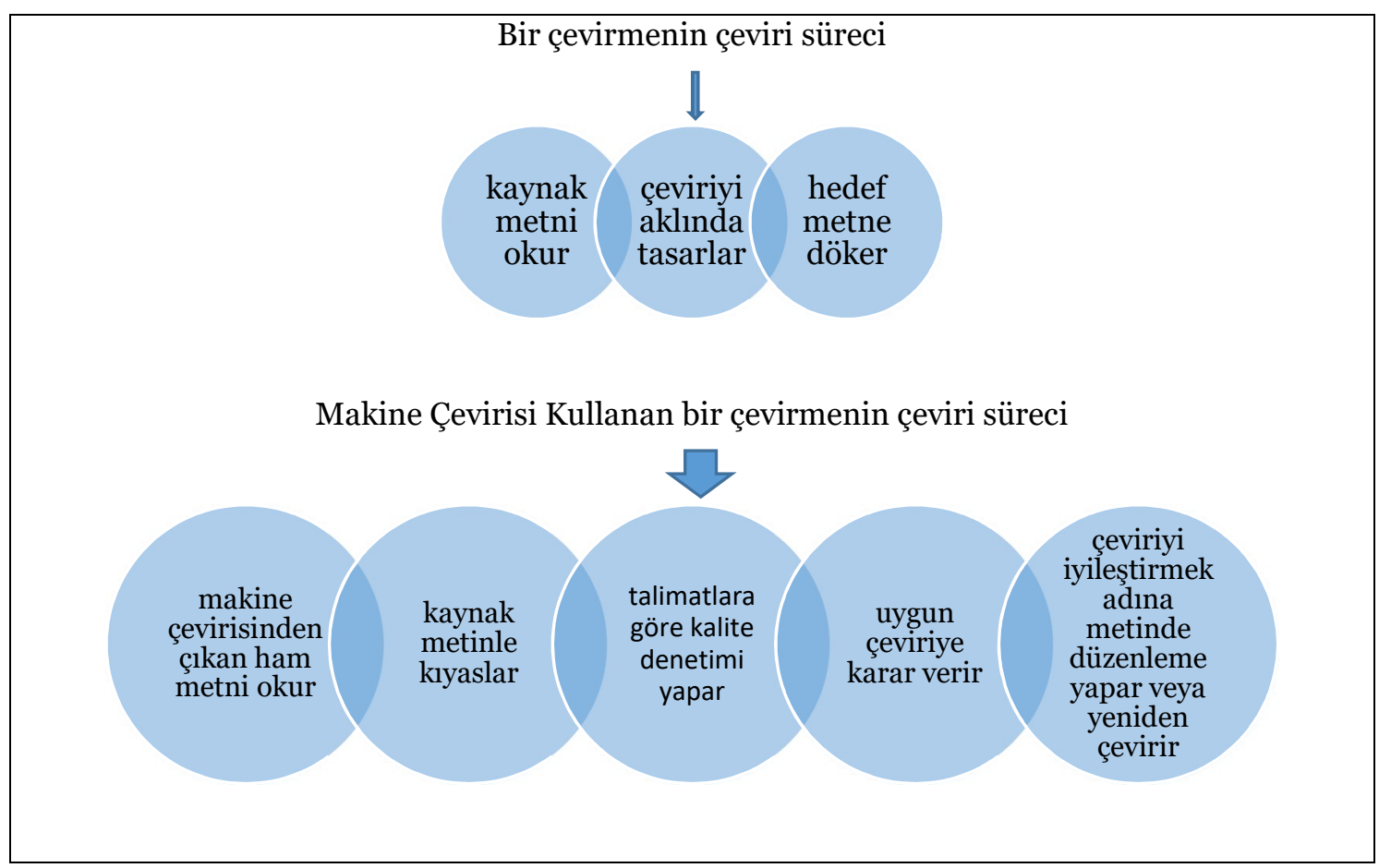

Şekil 2. Makine çevirisi kullanan ve kullanmayan çevirmenin çeviri süreci (Steurs, 2014) ${ }^{2}$

$\mathrm{Bu}$ şekli ayrıntılı olarak yorumlamaya geçmeden önce post-editing işleminin türlerine değinilmesinde fayda vardır. Birçok araştırmacı post-editing işlemini her ne kadar farklı adlar altında olsa da temel olarak iki kategoriye ayırmıştır. Bunlardan ilki makine çevirisinden çıkan ham metnin baştan sona yani tam olarak düzeltilmesi (full/complete post-editing) diğeri ise kısmi olarak düzeltilmesidir (light/rapid post-editing) (Almeida, 2013; Loffler-Laurian, 1986; Temizöz, 2014). Bunlardan ilki post-editing yaklaşımının hızlı ve dolayısıyla düşük maliyetli olmasına gönderme yaparken ikincisi ise post-editing yaklaşımının daha kapsamlı ve daha uzun süreye yayılmasına ve bunun sonucunda maliyetlerin daha yüksek olmasına gönderme yapmaktadır. Makine çevirisi sisteminden yararlanılarak çevrilen metnin nerede ve ne amaçla kullanılacağı seçilecek yaklaşımı belirlemede öncül kriter olarak kabul edilmektedir. Eğer makine çevirisi sadece ilgili metni bir önceki bölümde değinilen "anlama" amaciyla çevirmek için kullanılıyorsa kısmi düzeltme (light post-editing) yeterli olurken yayma (dissemination) amacında tam düzeltme (full post-editing) gerekli olacaktır. Ancak uygulamada bu ayrımı yapabilmek her zaman kolay olmamaktadır. Zira bir taraftan çeviriyi başlatan müşteri yüksek kalitede çeviri isterken diğer taraftan maliyetin düşük olmasını istemektedir. Bu bağlamda çevirmenin özellikle seçilecek postediting yaklaşımını da dikkate alarak bir dizi farklı beceriler geliştirmesi büyük önem arz etmektedir.

2 Şekilde geçen ifadeler Türkçeye bu metnin yazarı tarafından çevrilmiştir. 


\title{
4. Makine çevirisinin çeviribilim ve akademik çeviri eğitimi açısından önemi
}

Tarihsel süreç içerisinde çeviriye dair tanımlara bakıldığında çevirinin bir dizi farklı anlamının olduğu görülmektedir. Ancak bu tanımların neredeyse hepsinde ortak olan nokta "çeviri sözcüğünün, bir çalışma alanına (yani Çeviribilime), bir çeviri ürününe (yani çevrilen metne) ya da çeviri sürecine (yani çeviri ortaya koyma eylemine)" gönderme yaptı̆̆ıdır (Munday, 2008, s.5). Bu tanım makine çevirisinin geçirdiği evrim düşünüldüğünde 200o'li yllara kadar geçerliliğini korumuştur. Ancak makine çevirisinin günden güne artan şekilde kullanımı çeviride insan müdahalesinin azalmasına yol açmıştır. Dolayısıyla yalnız "çevirmen" tanımı değişmekle kalmayıp aynı zamanda "çeviri” tanımı da değişikliğe uğramıştır (O’Thomas, 2017). Bu hususta O’Thomas (2017) bu evrimin daha ileri boyutlara ulaşıp bir paradigma değişimi yaşanacağını şöyle ifade etmektedir:

\begin{abstract}
Makine çevirisinin günden güne büyüyen çeviri belleği veri tabanı ile birleşmesi, çevirilerin yapılma şeklinde belirgin bir paradigma değişiminin temelini atıp hem çeviri sürecinde hem de çeviri piyasasında kalıcı bir etki yaratacaktır. Özellikle edebi çevirmenin rolü, eninde sonunda belirli bir bireyin çeviri belleğini edinen bir yazılımın kapsamına girecektir. Teknolojiye ilişkin şu anki bilgi birikimimiz ve deneyimimizle bile bir bireyin tercih ettiği sözcük setlerini ve onların farklı dillerdeki kullanımını benimseyebilen ve taklit edebilen bir yazılımı hayal etmek güç değil. Bunları bir çeviri belleğine işleyen yazılım, bir çevirmenin yapabileceğine benzer çeviriler üretebilir ve hatta ölümünden sonra belirli bir çevirmen tarafından yapılan çevirilere benzer çevirileri yapma imkânı sunabilir (s.287).
\end{abstract}

Makine çevirisinin önemi bu kadar açlkken akademik çeviri eğitimi veren kurumların bu yönelime sırt çevrilmesi düşünülemez. Bununla birlikte literatüre bakıldığında özellikle 200o'lerin başına kadar yapılan çalışmalarının çoğunun akademik çeviri eğitimi bağlamından ziyade ya mühendisler tarafından ya da iyi ihtimalle çeviri piyasasında profesyonel çevirmenler üzerine gerçekleştirildiği görülmektedir. Ancak özelikle son on yll içerisinde bu konuya akademik çeviri eğitimi bağlamında değinen farklı çalışmalar ortaya konmuştur (Läubli, Fishel, Massey, Ehrensberger, \& Volk, 2013; O’Brien, 2012; Şahin, 2015; Witczak, 2016). Bu bağlamda O’Brien (2012) yapılan çalışmalarda öğrenciler ve yeni mezunlar gibi profesyonel deneyimi biriktirme anlamında kariyerlerinin henüz başında olan acemi çevirmenlerin uzun süreli deneyim sahibi profesyonel çevirmenlere kıyasla makine çevirisinden daha fazla yararlanabileceğinin belirtildiğini ifade etmektedir. Dewi (2015) ise çevirmen eğitiminde öğrencilerin paydaşlardan biri olduğunun altını çizmektedir. Dolayısıyla makine çevirisinin öğretimi ve bu konu üzerine akademik bağlamda çalışma yapılması büyük önem arz etmektedir. Buna rağmen akademik çeviri eğitimi veren kurumların teknolojik gelişmelerin gerisinde kaldığı yani "kurumsal geç kalmışlı" (Pym, 2011) yaşadığı görülmektedir. Bunun nedenini Austermühl (2013) maddeler halinde şöyle özetlemektedir:

Makine çevirisi, çeviri belleği gibi sistemlerin genelde üniversitelerin dışında yani çeviri şirketlerinde veya çeviri bölümü olmayan üniversitelerde geliştirilmesi

Bu araçlar konusunda, bu araçların çeviri sürecine ve ürününe etkisi konusunda yeteri kadar deneysel çalışmanın olmaması

Çeviri eğitimi veren çoğu kişinin çeviri teknolojilerini anında ve düzenli olarak derslerine entegre etme konusunda yeterli profesyonel ve/veya teknolojik uzmanlığa sahip olmaması

Çeviri müfredatlarında öğretilecek çok fazla konunun olması

Müfredatlar üzerinde yönetimlerin merkezi bir kontrolünün olması; finansal kaynaklara erişim konusunda yetersiz kalınması

Eğitim veren kişilerin ve öğrencilerin tutumlarının olumsuz olması (s.327). 
Sorunlar bu kadar açıkken akademik çeviri eğitimi veren kurumların, müfredatlarına doğrudan makine çevirisi konusunu ele alan bir ders eklemeleri bu sorunların çözümüne giden ilk adım olacaktır. Bu anlamda Guerberof (2008) çeviride düzeltmeyi öğreten bir kursun geliştirilebileceğini, bu kursta postediting bağlamında farklı makine çevirisi teknolojilerine ilişkin arka plan bilgisinin verilebileceğini ve öğrencilere makine çevirisinden çıkan ham metni düzeltmede uygulamalı ödevlerin yararlı olacağını vurgulamıştır. Bu konuda Mellinger (2017) ise müfredatların düzenlenmesine ilişkin yaklaşımların, çeviri piyasasının gereksinimleriyle uyum içerisinde olması gerektiğini, böylece öğrencilerin mezuniyet sonrası piyasada doğru yerlerde konumlanabileceğini yinelemiştir.

\section{Sonuç}

Makine çevirisinin artık bir ihtiyaç olduğu, ancak mevcut makine çevirisi sistemlerinin beklenen kalitede çeviriler üretmediği açıktır. Bu nedenle Makine Çevirisi Sonrası Düzeltme İşlemi (post-editing) çeviri piyasasında önemli bir yer edinmiştir. Çeviri hacminin yerelleştirme gibi faaliyetlerle günden güne genişlediği gerçeği dikkate alınırsa post-editing işleminin uzun süre gündemde olacağı yadsınamaz bir gerçektir.

$\mathrm{Bu}$ çalışmada ilk olarak makine çevirisi sistemleri tarihsel süreç içinde ele alınıp bu sistemlerin geçirdiği evrim bağlamında post-editing işleminin kökenleri ve gerekçeleri sıralanmıştır. Bu bağlamda makine çevirisi çalışmalarının ivme kazandığı 1950'li yılların genel görünümüne ve büyük umutları söndüren ALPAC raporuna değinilmiştir. Bu doğrultuda ALPAC raporunun makine çevirisinden, Bilgisayar Destekli Çeviri aracı gibi sistemlere geçişi sağlamasına ve temel düzeyde dilbilimsel araştırmalara ağırlık verilmesi konusundaki çabaları desteklemesine değinilmiştir. Buna göre ALPAC raporu ilk başlarda her ne kadar makine çevirisine yönelik yatırımların kesilmesine neden olsa da arka planda çevirinin otomatikleştirilmesi hedefinin hep var olduğu sonucu çıkarılmıştır. Dolayısıyla buna yönelik çalışmaların arka planda sürdürüldüğü görülmüştür.

Çalışmanın ilerleyen kısımlarında makine çevirisi kullanımının gerekçeleri bağlamında bazı terimler tartışmaya açılmıştır. Bu terimlerin Türkçe karşılıkları yeniden bulunmaya çalışılmıştır. Daha sonra "post-editing" işlemine dair kapsamlı bir tanım verilip bu işlemin türlerinden bahsedilmiştir. Buna göre çevrilecek metnin yayımlanma amacına göre post-editing yaklaşımının seçilmesi gerektiği ve çevirmenlerin de bu post-editing yaklaşımlarına uygun beceriler geliştirmesi gerektiği sonucuna varılmıştır. Çalışmada ayrıca post-editing işleminin Çeviribilimde bir paradigma değişiminin yolunu açtığına değinilmiştir. Bu bağlamda gerek süreç gerekse ortaya konan ürün bakımından çeviri tanımı tartışlıp, eski tanımların artık değişime uğradığı sonucu çıkarılmıştır.

Makine çevirisinin önemi vurgulandıktan sonra akademik çeviri eğitimindeki yerine ve akademik kurumların çeviri teknolojilerinin öğretimine ilişkin genel durumlarına değinilmiştir. Buna göre akademik çeviri eğitimi veren kurumların "kurumsal geç kalmışlık" durumu içerisinde oldukları sonucuna varılmıştır. Bu kurumsal geç kalmışlık durumunun nedenleri listelenmiş bunların çözümüne ilişkin öneriler verilmiştir. Bu bağlamda makine çevirisini konu alan bir dersin bir an önce tüm çeviri bölümlerinin müfredatlarında yer alması gerektiği, böyle bir dersin ise makine çevirisine yönelik hem kuramsal hem de uygulamaya dayanan bilgi birikimini kapsamasının yararlı olacağı sonucuna varılmıştır.

Bu çalışmanın, Makine Çevirisi Sonrası Düzeltme İşlemi (post-editing) gibi güncel ve Çeviribilim alanını doğrudan ilgilendiren bir konuyu ele alması açısından öneme sahip olduğu ve bu alanda başka 
çalışmaların yapılmasını güdüleyeceği düşünülmektedir. Ayrıca her ne kadar istenen düzeyde olmasa da bu konuda özellikle İngilizce olmak üzere yabancı kaynak bulmak mümkündür. Ancak bu konuda yazılmış Türkçe kaynak yeteri sayıda değildir. Dolayısıyla çalışmanın Türkçe yapılmış olmasının ülkemizde İngilizce dışındaki dillerde Çeviribilim üzerine çalışan araştırmacılar için bir kaynak ve bir başlangıç noktası oluşturacağı düşünülmektedir. Çalışmada özellikle terimlere Türkçe karşılık aranmıştır, ancak hala üzerinde hemfikir olunmayan terimler vardır. Dolayısıyla gelecekte yapılacak araştırmalarda bu terimlerin daha detaylı incelenmesi alana büyük katkı sağlayacaktır.

\section{Kaynakça}

Allen, J. (2003). Post-Editing. Içinde H. Somers (Ed.), Computers and Translation (ss. 297-319). Amsterdam: John Benjamins Publishing Company.

Almeida, G. de. (2013). Translating the post-editor: An investigation of post-editing changes and correlations with professional experience across two Romance languages (Ph.D. Thesis). Dublin City University, Dublin.

Austermühl, F. (2013). Future (and not-so-future) trends in the teaching of translation technology. Revista Tradumàtica: tecnologies de la traducció, (11), 326-337.

Balkul, H. İ., \& Toptan, D. Ö. (2019). The Evaluation of Workflow on Virtual Translation Platforms within the Framework of Translational Action Theory: The Case of Proz.com Website. International Journal of Languages' Education and Teaching, 7(2), 222-235.

Bellos, D. (2011). Is That a Fish in Your Ear? Translation and the Meaning of Everything. New York: Farrar.

Chan, S. (2004). A dictionary of translation technology. Hong Kong: Chinese University Press.

Chan, S. (2015). The development of translation technology. Içinde S. Chan (Ed.), The Routledge encyclopedia of translation technology (ss. 3-32). New York: Routledge.

Dewi, H. D. (2015). Comparing two translation assessment models: Correlating student revisions and perspectives (Ph.D. Thesis). Kent State University, Kent, Ohio.

Doherty, S. (2012). Investigating the Effects of Controlled Language on the Reading and Comprehension of Machine Translated Texts: A Mixed-Methods Approach (Ph.D. Thesis). Dublin City University, Dublin.

Fiederer, R., \& O’Brien, S. (2009). Quality and Machine Translation: A realistic objective? The Journal of Specialised Translation, 11(1), 52-74.

Forcado, M. L. (2010). Machine Translation Today. Içinde Y. Gambier \& L. Van Doorslaer (Ed.), Handbook of translation studies. Vol. 1. Amsterdam: Benjamins.

Gordin, M. D. (2016). The Dostoevsky machine in Georgetown: Scientific translation in the Cold War. Annals of Science., 208-223.

Guerberof, A. (2008). Productivity and quality in the post-editing of outputs from translation memories and machine translation (Ph.D. Thesis). Universitat Rovira i Virgili, Tarragona.

Hutchins, J. (1995). Machine Translation: A Brief History. Içinde E. F. K. Koerner \& R. E. Asher (Ed.), Concise History of the Language Sciences: From the Sumerians to the Cognitivists (ss. 431-445). Geliş tarihi gönderen http://hutchinsweb.me.uk/ConcHistoryLangSci-1995.pdf

Hutchins, J. (2001). Machine translation and human translation: In competition or in complementation. International Journal of Translation, 13(1-2), 5-20.

Hutchins, J. (2003). Commercial Systems The State of the Art. Içinde H. Somers (Ed.), Computers and Translation (ss. 161-175). Amsterdam: John Benjamins Publishing Company.

Hutchins, J., \& Somers, H. L. (1992). An introduction to machine translation. Manchester: Academic Press. 
Kovačević, M. (2014). Post-editing of machine translation output with and without source text. Hieronymus, 1(1), 82-104.

Läubli, S., Fishel, M., Massey, G., Ehrensberger, M., \& Volk, M. (2013). Assessing post-editing efficiency in a realistic translation environment. Proceedings of MT Summit XIV Workshop on Post-Editing Technology and Practice, 83-91. Nice.

Loffler-Laurian, A.-M. (1986). Post-édition rapide et post-édition conventionelle: L Deux modalités d〉’ une activité spécifique. Multilingual Journal of Cross-Cultural and Interlanguage Communication, 5(2), 81-88.

Loffler-Laurian, A.-M. (1996). La traduction automatique. Paris: Presses universitaires du Septentrion.

Mellinger, C. D. (2017). Translators and machine translation: Knowledge and skills gaps in translator pedagogy. Interpreter and Translator Trainer.

Mossop, B. (2014). Revising and editing for translators. London: Routledge.

Munday, J. (2008). Introducing Translation Studies. London; New York: Routledge.

Munteanu, D. (2016, Ağustos). Machine Translation goes Neural. MultiLingual. Geliş tarihi gönderen file://C:/Users/asa/Downloads/SDLwhitePaper161webVersion_tcm73-107239.pdf

Nyberg, E., Mitamura, T., \& Olaf Huijsen, W. (2003). Controlled language for authoring and translation. Içinde H. Somers (Ed.), Computers and Translation (ss. 245-283). Amsterdam: John Benjamins Publishing Company.

O’Brien, S. (2006). Machine-translatability and post-editing effort: An empirical study using translog and choice network analysis (Ph.D. Thesis). Dublin City University, Dublin.

O'Brien, S. (2012). Translation as human-computer interaction. Translation Spaces, 1(1), 101-122.

O'Thomas, M. (2017). Humanum ex machine: Translation in the post-global, posthuman world. Target 29(2), 284-300.

Pugh, J. (1992). The story so far: An evaluation of machine translation in the world today. Içinde J. Newton (Ed.), Computers in translation: A practical appraisal. London: Routledge.

Pym, A. (2011). What technology does to translating. The International Journal for Translation \& Interpreting Research, 3(1), 1-9.

Quah, C. K. (2006). Translation and technology. New York: Palgrave Macmillan.

Qun, L., \& Xiaojun, Z. (2015). Machine Translation General. Içinde S. Chan (Ed.), The Routledge encyclopedia of translation technology. London.

Reichert, C. (2016, Eylül 28). Google announces Neural Machine Translation to improve Google Translate. Geliş tarihi 19 Kasım 2018, gönderen https://www.zdnet.com/article/googleannounces-neural-machine-translation-to-improve-google-translate/

Rico, C, \& Torrejon, E. (2004). Controlled Translation as a New Translation Scenario-Training the Future User. Translating and the Commputer, (26), 4.

Rico, Celia, \& Torrejón, E. (2012). Skills and Profile of the New Role of the Translator as MT Post-editor. Revista Tradumàtica: tecnologies de la traducció, (10), 166-178.

Steurs, F. (2014). Man vs. Machine (Translation): MT as a Tool for Translators. From Classroom to Workplace. Program adı: 14th Annual Portsmouth Translation Conference, Portsmouth.

Şahin, M. (2013). Çeviri ve Teknoloji. İzmir: İzmir Ekonomi Üniversitesi Yayınları.

Şahin, M. (2015). Çevirmen Adaylarının Gözünden İngilizce-Türkçe Bilgisayar Çevirisi ve Bilgisayar Destekli Çeviri: Google Deneyi. Hacettepe Üniversitesi Çeviribilim ve Uygulamaları Dergisi, 21, 43-6o.

Temizöz, Ö. (2014). Postediting machine translation output and its revision: Subject-matter expert experts versus professional translators (Ph.D Thesis). Universitat Rovira i Virgili, Tarragona. 
472 / RumeliDE Journal of Language and Literature Studies 2019.S6 (November)

A comprehensive review of the machine translation post-editing / C. Çetiner (pp. 462-472)

Vashee, K. (2013). Understanding the economics of machine translation. Translation Spaces, 2(1), 125149.

Witczak, O. (2016). Incorporating post-editing into a computer-assisted translation course. A study of student attitudes. Journal of Translator Education and Translation Studies, 1(1), 33-55. 